\title{
SISTEM PENDUKUNG KEPUTUSAN PENENTUAN HARGA JUAL SEPEDA MOTOR BEKAS DENGAN PENDEKATAN LOGIKA FUZZY INFRENCE SYSTEM MAMDANI
}

\author{
Imam Sunoto \\ Fakultas Teknik Matematika dan IPA, Program Studi Teknik Informatika \\ Universitas Indraprasta PGRI \\ Email: raiderimam@gmail.com \\ Lukman \\ Fakultas Teknik Matematika dan IPA, Program Studi Teknik Informatika \\ Universitas Indraprasta PGRI \\ Email: 1kmnaja51@gmail.com
}

\begin{abstract}
ABSTRAK
Perkembangan teknologi yang sangat cepat dalam bidang transportasi mengakibatkan cepatnya bermunculan sepeda motor-sepeda motor baru dalam waktu dekat. Sehingga memicu meningkatnya tingkat pembelian sepeda motor baru, dan juga meningkatkan tingkat penjualan sepeda motor bekas. Dikarenakan mayoritas masyarakat akan menjual sepeda motor lamanya terlebih dahulu untuk kemudian beralih membeli sepeda motor yang lebih baru dengan spesifikasi yang lebih canggih. Hanya saja selama ini transaksi jual beli sepeda motor bekas yang dilakukan oleh dealersepeda motor masih menggunakan cara manual dalam penentuan harga jualnya, yaitu berdasarkan perkiraan dimana hasilnya kurang akurat dan tidak sesuai dengan kondisi dari sepeda motor tersebut. Untuk itu dibutuhkan suatu sistem yang dapat menentukan harga jual sepeda motor bekas dengan akurat sesuai dengan kondisi sepeda motor tesebut dan juga sesuai dengan harga jual dipasaran. Dalam penelitian ini dalam penentuan harga jualnya menggunakan logika fuzzy infrence system (fis) Mamdani. Dengan adanya sistem penentuan harga jual tadi diharapkan dapat memudahkan pihak dealer sepeda motor dalam menentukan harga jual sepeda motor bekas dengan lebih akurat sesuai dengan kondisi dari sepeda motor yang akan dijual. Hasil dari penelitian ini yaitu berupa prototype yang dapat memproses masukan berupa kondisi fisik, aksesoris, minat pasar, dan harga beli baru dari sepeda motor menjadi keluaran berupa harga jual bekas sepeda motor bekas.
\end{abstract}

Kata kunci: penentuan, logika fuzzy mamdani, harga jual, sepeda motor bekas.

\section{ABSTRACT}

Rapid technological developments in the field of transportation resulted in fast-emerging new motorcycle in the near future. So as trigger increased levels of purchasing a new motorcycle, and also increase the level of sales of second-hand motorcycle. Because the majority of people will sell the first ever motorcycle to then switch buy newer motorcycle with more advanced specs. It's just been buying and selling second-hand motorcycle made by motorcycle dealer still use the manual method of determining the selling price, which is based on estimates where the results are less accurate and not in accordance with the conditions of the motorcycle. For that we need a system that can determine the selling price of a used motorcycle with accurate according to the proficiency level motorcycle conditions and also in accordance with the market price. In this study the method of determining the selling price using Mamdani fuzzy infrence system (fis) logic. With a system of determining the selling price was expected to facilitate the cellular store in determining the selling price of a used sepeda motor more accurately in accordance with the conditions of a motorcycle to be sold. Results from this study is a prototype that can process input in the form of physical condition, accessorie, market interest, and the new purchase price of a motorcycle into the output of the selling price of a used motorcycle.

Keywords: determining, mamdani fuzzy logic, selling price, second-hand motorcycle.

\section{PENDAHULUAN}

\subsection{Latar Belakang}

Perkembangan teknologi yang sangat cepat dari tahun ke tahun memicu terjadinya banyak perubahan. Salah satunya adalah pada bidang transportasi. Masyarakat yang dulu hanya berjalan kaki atau naik angkot dalam berpergian, sekarang sudah menggunakan sepeda motor yang lincah, irit, serta harga 
yang terjangkau. Untuk itu para pabrikansepeda motor saling bersaing dalam membuat sepeda motor yang semakin canggih, hal ini menyebabkan cepatnya bermunculan sepeda motor-sepeda motor baru dalam waktu singkat. Sehingga memicu meningkatnya tingkat pembelian sepeda motor baru, dan penjualan sepeda motor bekas. Dikarenakan mayoritas masyarakat akan menjual sepeda motor lamanya terlebih dahulu untuk kemudian beralih membeli sepeda motor yang lebih baru dengan spesifikasi yang lebih canggih.

Hanya saja kegiatan transaksi penjualan yang dilakukan oleh dealer sepeda motor masih menggunakan cara manual dalam penentuan harga jualnya, dimana penentuan harga jualnya hanya berdasarkan perkiraan. Hal ini menyebabkan terjadinya perbedaan dalam menentukan harga jual sepeda motor antara karyawan dealer yang berbeda, dan itu pun harus dikonfirmasi terlebih dahulu oleh pemilik dealer untuk disetujui agar terjadi kesepakatan harga jual antara pihak dealer dan pihak penjual sepeda motor. Sehingga proses dalam penentuan harga jual menjadi lebih lama.

Diharapkan dengan adanya sistem ini dapat membantu proses penentuan harga jual sepeda motor bekas dengan lebih cepat. Dan juga keakuratannya akan lebih terjamin dimana penentuannya didasarkan pada kriteria dan bobot yang telah ditetapkan sebelumnya, sehingga hal ini dapat memperlancar transaksi jual beli yang terjadi pada dealer sepeda motor. Selain itu dengan penggunaan sistem ini dapat meningkatkan kepercayaan pihak yang menjual sepeda motor kepada pihak dealer sepeda motor dikarenakan penentuan harga jual sepeda motor tidak hanya didasarkan pada perkiraan saja melainkan melalui perhitungan bobot pada tiap-tiap kriteria yang telah ditentukan.

\subsection{Pengertian Sistem Pendukung Keputusan}

Sistem adalah suatu kesatuan usaha yang terdiri dari bagian-bagian yang berkaitan satu sama lain yang berusaha mencapai suatu tujuan dalam suatu lingkungan kompleks. Pengertian tersebut mencerminkan adanya beberapa bagian dan hubungan antara bagian, ini menunjukkan kompleksitas dari sistem yang meliputi kerja sama antara bagian yang independent satu sama lain. Selain itu dapat dilihat bahwa sistem berusaha mencapai tujuan. Pencapaian tujuan ini menyebabkan timbulnya dinamika, perubahan-perubahan yang terus-menerus perlu dikembangkan dan dikendalikan [1].

Sistem pendukung keputusan sebagai sekumpulan prosedur berbasis model untuk data pemrosesan dan penilaian guna membantu para manajer mengambil keputusan untuk sukses, sistem tersebut haruslah sederhana, cepat, mudah dikontrol, adaptif lengkap dengan isu-isu penting, dan mudah berkomunikasi [2].

Dari definisi tersebut, dapat diindikasikan empat karakteristik utama dari sistem pendukung keputusan, yaitu:

1. Sistem pendukung keputusan menggabungkan data dan model menjadi satu bagian.

2. Sistem pendukung keputusan dirancang untuk membantu para manajer (pengambil keputusan) dalam proses pengambil keputusan dari masalah yang bersifat semi struktural (tidak terstruktur).

3. Sistem pendukung keputusan lebih cenderung dipandang sebagai penunjang penilaian manajer dan sama sekali bukan untuk menggantikannya.

4. Teknik sistem pengambil keputusan dikembangkan untuk meningkatkan efektivitas dari pengambil keputusan.

Aplikasi dari sistem pengambil keputusan baru dapat dikatakan berhasil atau bermanfaat, jika terdapat kondisi sebagai berikut:

1. Eksistensi dari basis data yang sangat besar, sehingga sulit mendayagunakannya.

2. Kepentingan adanya transformasi dan komputasi pada proses pencapaian keputusan.

3. Adanya keterbatasan waktu, baik dalam penentuan hasil maupun dalam prosesnya.

4. Kepentinganakan penilaian atas pertimbangan akal sehat untuk menentukan dan mengetahui pokok permasalahan, serta pengembangan alternatif dan penilain solusi.

\subsection{Rumusan Masalah}

Dari latar belakang diatas maka didapatkan rumusan masalah sebagai berikut, bagaimana membuat sistem penentuan harga jual sepeda motor bekas agar dapat membantu dealer sepeda motor dalam menentukan harga jual sepeda motor bekas dengan akurat dan mudah, sesuai dengan kriteria dan bobot yang telah ditentukan?

\subsection{Batasan Masalah}

Dikarenakan banyaknya merk, tipe serta jenis sistem operasi dari sepeda motor itu sendiri dan juga keterbatasan pengetahuan dari penulis, maka penulis menetapkan ruang lingkup dan batasan masalah pada penelitian ini yaitu: 
a. Penentuan harga jual hanya terbatas pada merk sepeda motorHonda, Yamaha, Suzuki, dan Kawasaki.

b. Variabel fuzzy yang digunakan meliputi variabel input yaitu Kondisi Fisik, Kondisi Aksesoris, Minat Pasar, dan Harga Beli Baru. Serta variabel output yaitu Harga Jual Bekas.

\subsection{Tujuan}

Berdasarkan rumusan masalah diatas, maka tujuan dari penelitian ini adalah:

a. Membangun sistem untuk menentukan harga jual sepeda motor bekas.

b. Meningkatkan keakuratan dan kemudahan dalam penentuan harga jual sepeda motor bekas yang didasarkan pada kriteria dan bobot yang telah ditentukan.

c. Mengimplementasikan logika fuzzy infrence system Mamdani yang dapat digunakan untuk sistem penentuan harga jual sepeda motor bekas.

\subsection{Manfaat}

Manfaat dari penelitian ini adalah:

a. Dapat membantu dealer sepeda motor dalam menentukan harga jual sepeda motor bekas.

b. Dapat mempercepat proses penentuan harga jual.

c. Dapat menghasilkan harga jual sepeda motor yang lebih akurat dengan data-data yang jelas.

\section{METODOLOGI PENELITIAN}

\subsection{Pengertian Fuzzy Logic}

Sebelum munculnya teori fuzzy logic dikenal sebuah logika tegas (crisp logic) yang memiliki nilai benar dan salah secara tegas. Sebaliknya fuzzy logic adalah Suatu logika yang memiliki nilai kekaburan atau kesamaran (fuzzyness) antara benar dan salah. Dalam teori fuzzy logic suatu nilai bisa bernilai benar dan salah secara bersamaan. Namun berapa besar kebenaran dan kesalahan suatu nilai tergantung pada bobot keanggotaan yang dimilikinya. Orang yang belum mengenal fuzzy logic pasti akan mengira bahwa fuzzy logic adalah suatu yang amat rumit dan tidak menyenangkan. Namun, sekali orang mengenalnya, ia pasti akan sangat tertarik dan akan menjadi pendatang baru untuk ikut serta mempelajarinya. Fuzzy logic dikatakan sebagai logika baru yang lama, sebab ilmu tentang fuzzy logic modern dan metodis baru ditemukan beberapa tahun yang lalu, padahal sebenarnya konsep tentang fuzzy logic itu sendiri sudah ada pada diri kita sejak lama. Fuzzy logic adalah suatu cara yang tepat untuk memetakan suatu ruang input ke dalam suatu ruang output [3].

\subsection{Logika Fuzzy Infrence System Mamdani}

Logika fuzzy infrence system Mamdani sering juga dikenal dengan nama Metode Max-Min. Metode ini diperkenalkan oleh Ebrahim Mamdani pada tahun 1975 [3]. Untuk mendapatkan output, diperlukan 4 tahapan:

1. Pembentukan himpunan fuzzy. Menentukan variabel fuzzy dan himpunan fuzzinya. Kemudian tentukan derajat keanggotaan antara data masukan fuzzy dengan himpunan fuzzy yang telah didefenisikan untuk setiap variabel masukan sistem dari setiap aturan fuzzy.

2. Aplikasi fungsi implikasi pada logika fuzzy infrence system Mamdani. Fungsi implikasi yang digunakan adalah min. Hasil implikasi fuzzy dari setiap aturan ini kemudian digabungkan untuk menghasilkan keluaran infrensi fuzzy.

3. Komposisi Aturan (rule). Tidak seperti penalaran monoton, apabila sistem terdiri dari beberapa aturan, maka infrensi diperoleh dari kumpulan dan korelasi antar aturan. Ada 3 metode yang digunakan dalam melakukan inferensi sistem fuzzy, yaitu: max, additive dan Jumlah babilistik OR.

4. Penegasan (defuzzy). Input dari Proses defuzzifikasi adalah suatu himpunan fuzzy yang diperoleh dari komposisi aturan-aturan fuzzy, sedangkan output yang dihasilkan merupakan suatu bilangan pada domain himpunan fuzzy tersebut.

Motivasi utama teori fuzzy logic adalah memetakan sebuah ruang input ke dalam ruang output dengan menggunakan IF-THEN Rule. Pemetaan dilakukan dalam suatu FIS, urutan rule bisa sembarang. FIS mengevaluasi semua rule secara simultan untuk menghasilkan kesimpulan. Oleh karenanya, semua rule harus didefinisikan lebih dahulu sebelum kita membangun sebuah FIS yang akan digunakan untuk menginterpretasikan semua rule tersebut. Mekanisme dalam FIS bisa dirangkum yaitu: FIS adalah sebuah 
metode yang menginterpretasikan harga-harga dalam vektor input, menarik kesimpulan berdasarkan sekumpulan IF-THEN rule yang diberikan, dan kemudian menghasilkan vektor output [4].

\subsection{Proses Penjualan Sepeda motor}

Pada proses penjualan sepeda motor beberapa prosedur harus dilakukan oleh pihak dealer sepeda motor terhadap sepeda motor yang akan dijual. Pertama yaitu mengecek dan mencocokan kesamaan no mesin dan rangka pada sepeda motor dengan no mesin dan rangka yang ada pada surat-surat dari sepeda motor tersebut baik STNK ataupun BPKB. Selanjutnya menanyakan kepada pemilik sepeda motor apakah sepeda motor sudah pernah dibeli orang lain sebelumnya.

Terakhir mengecek kelengkapan dari sepeda motor tersebut seperti STNK, BPKB, Faktur, dan lainlain sesuai dengan merk dan tipe sepeda motor tersebut. Setelah semua prosedur dilakukan dan memenuhi syarat maka barulah dilakukan penafsiran harga jual dari sepeda motor bekas tersebut.

\subsection{Penentuan Harga Jual Bekas}

Setelah prosedur pengecekan pada proses penjualan dilakukan, baru penentuan harga jual bekas dilakukan. Dan yang menjadi faktor penentu tinggi rendahnya harga jual bekas adalah yang pertama adalah kondisi fisik dari sepeda motor tersebut. Faktor berikutnya adalah kondisi aksesorissepeda motor.

Selanjutnya faktor yang menjadi penentu harga jual bekas adalah minat pasar dari sepeda motor tersebut. Faktor lainnya yang menjadi penentu harga jual bekas adalah harga beli baru sepeda motor tersebut. Dan yang menjadi faktor terakhir adalah harga jual bekas dipasaran, dimana menjadi acuan paling penting dalam penentuan harga jual bekas, karena harga jual dipasaran lah yang menjadi dasar harga dari penentuan harga jual sepeda motor bekas.

\section{HASIL PENELITIAN DAN PEMBAHASAN}

\subsection{Penerapan Logika}

Dalam penyusunan penerapan logika fuzzy infrence system Mamdani untuk menentukan harga jual sepeda motor bekas ini terdapat beberapa langkah yang harus dilakukan untuk mendapatkan data yang valid dalam penyusunannya. Hal tersebut dilakukan untuk mendapatkan hasil berupa harga jual bekas yang sesuai dengan harga jual bekas dipasaran.

Setelah dilakukan perhitungan dan percobaan, maka didapatlah hasil penentuan harga jual sepeda motor bekas dengan menerapkan logika fuzzy infrence system Mamdani dengan Matlab.

\subsubsection{Menentukan Himpunan Fuzzy}

\section{a) Variabel Kondisi Fisik}

Variabel input kondisi fisik merupakan kondisi luar yang tampak atau kelihatan dari body atau badan dari sepeda motor, semakin banyaknya goresan yang terlihat pada body akan semakin menurunkan harga jual. Range dan domain dari variabel kondisi fisik dapat terlihat pada tabel di bawah ini.

Tabel 1. Kondisi fisik

\begin{tabular}{cccc}
\hline No & Himpunan & Range & Domain \\
\hline 1 & Kurang & $1-10$ & $0-4$ \\
2 & Sedang & $1-10$ & $3-7$ \\
3 & Bagus & $1-10$ & $6-10$ \\
\hline
\end{tabular}

Variabel kondisi fisik dibagi menjadi 3 himpunan fuzzy yaitu: Kurang, Sedang, dan Bagus. Himpunan fuzzy Kurang akan memiliki domain [0 - 4] dimana derajat keanggotaan Kurang tertinggi $(=1)$ terletak pada angka $0-3$. Himpunan fuzzy Sedang memiliki domain [3 - 7] dimana derajat keanggotaan Sedang tertinggi $(=1)$ terletak pada nilai 5. Himpunan fuzzy Bagus akan memiliki domain [6 - 10] dimana derajat keanggotaan Bagus tertinggi $(=1)$ terletak pada angka $\geq 7$. Variabel kondisi fisik dipresentasikan dengan fungsi keanggotaan bahu dan segitiga. Hasil pengolahan himpunan dengan program Matlab dapat terlihat seperti pada gambar di bawah ini. 


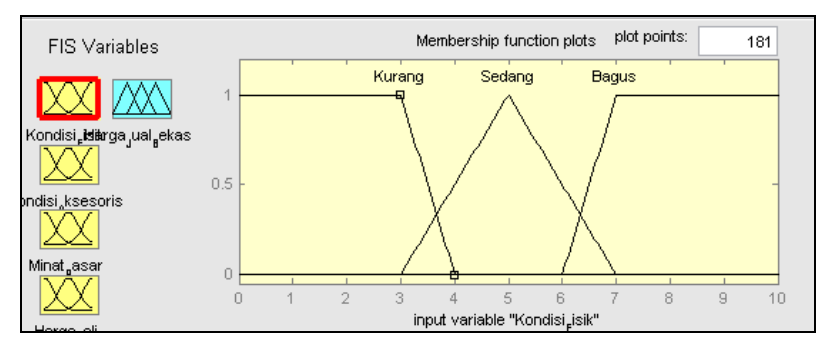

Gambar 1. Grafik Variabel Kondisi Fisik

Dan persamaannya.

$$
\begin{aligned}
& \mu \text { Kurang }[x]=\left\{\begin{array}{l}
1 \\
(4-x) /(4-3) \\
0
\end{array}\right. \\
& \mu \text { Sedang }[x]=\left\{\begin{array}{l}
(x-3) /(4-3) \\
(7-x) /(4-3) \\
0
\end{array}\right. \\
& \mu \operatorname{Bagus}[x]=\left\{\begin{array}{l}
0 \\
(x-6) /(10-6) \\
1
\end{array}\right. \\
& \begin{array}{c}
; 0 \leq x \leq 3 \\
; 3 \leq x \leq 4 \\
\quad x \geq 4 \\
; 3 \leq x \leq 4 \\
; 4 \leq x \leq 7 \\
; x \leq 3 \text { atau } x \geq 7 \\
\quad x \leq 6 \\
; \quad 6 \leq x \leq 7 \\
; 7 \leq x \leq 10
\end{array}
\end{aligned}
$$

b) Variabel Kondisi Aksesoris

Variabel input kondisi aksesoris merupakan kondisi kelengkapan pendukung utama yang ada pada sepeda motor tersebut. Aksesoris tersebut antara lain meliputi striping, warna cat, dan aksesoris lainnya. Apabila terdapat kekurangan dari kondisi normal pada aksesoris tadi, maka akan mengurangi harga jual. Range dan domain dari variabel kondisi aksesoris dapat terlihat pada tabel di bawah ini.

Tabel 2. Kondisi aksesoris

\begin{tabular}{cccc}
\hline No & Himpunan & Range & Domain \\
\hline 1 & Kurang & $1-10$ & $0-4$ \\
2 & Sedang & $1-10$ & $3-7$ \\
3 & Baik & $1-10$ & $6-10$ \\
\hline
\end{tabular}

Variabel kondisi aksesoris dibagi menjadi 3 himpunan fuzzy yaitu: Kurang, Sedang, dan Baik. Himpunan fuzzy Kurang akan memiliki domain [0 - 4] dimana derajat keanggotaan Kurang tertinggi (=1) terletak pada angka 0 - 3. Himpunan fuzzy Sedang memiliki domain [3 - 7] dimana derajat keanggotaan Sedang tertinggi $(=1)$ terletak pada nilai 5. Himpunan fuzzy Baik akan memiliki domain [6 - 10] dimana derajat keanggotaan Baik tertinggi $(=1)$ terletak pada angka $\geq 7$. Variabel kondisi aksesoris dipresentasikan dengan fungsi keanggotaan bahu dan segitiga. Hasil pengolahan himpunan dengan program Matlab dapat terlihat seperti pada gambar di bawah ini.

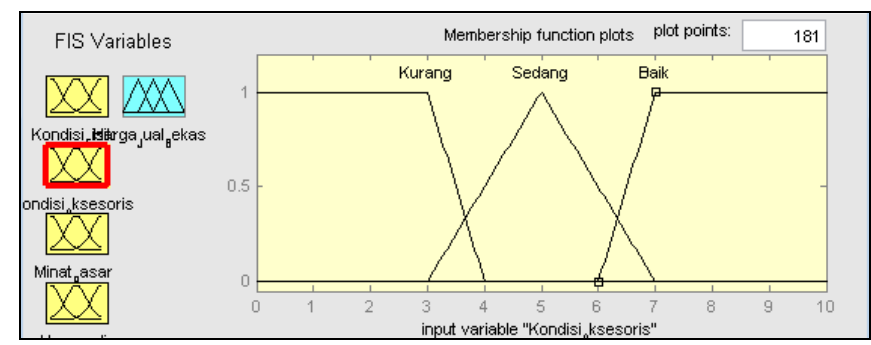

Gambar 2. Grafik Variabel Kondisi Aksesoris

Dan persamaannya.

$\mu \operatorname{Kurang}[\mathrm{x}]=\left\{\begin{array}{l}1 \\ (4-x) /(4-3) \\ 0\end{array}\right.$

$; 0 \leq \mathrm{x} \leq 3$

$3 \leq \mathrm{x} \leq 4$

; $\quad x \geq 4$

$\mu$ Sedang $[x]=\left\{\begin{array}{l}(x-3) /(4-3) \\ (7-x) /(4-3) \\ 0\end{array}\right.$ 


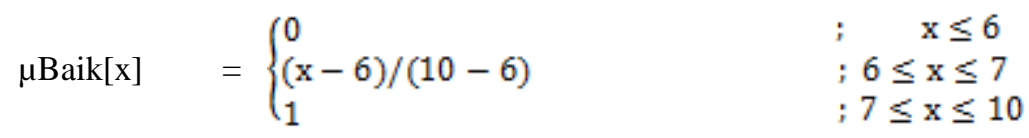

c) Variabel Minat Pasar

Variabel input minat pasar merupakan banyak sedikitnya permintaan suatu sepeda motor, dimana hal ini mempengaruhi tinggi rendahnya harga jual bekas. Range dan domain dari variabel minat pasar dapat terlihat pada tabel di bawah ini.

\begin{tabular}{cccc}
\hline No & Himpunan & Range & Domain \\
\hline 1 & Rendah & $1-10$ & $0-4$ \\
2 & Sedang & $1-10$ & $3-7$ \\
3 & Tinggi & $1-10$ & $6-10$ \\
\hline
\end{tabular}

Variabel minat pasar dibagi menjadi 3 himpunan fuzzy yaitu: Rendah, Sedang, dan Tinggi. Himpunan fuzzy Rendah akan memiliki domain [0 - 4] dimana derajat keanggotaan Rendah tertinggi (=1) terletak pada angka 0 - 3. Himpunan fuzzy Sedang memiliki domain [3 - 7] dimana derajat keanggotaan Sedang tertinggi $(=1)$ terletak pada nilai 5. Himpunan fuzzy Tinggi akan memiliki domain [6 - 10] dimana derajat keanggotaan Tinggi tertinggi $(=1)$ terletak pada angka $\geq 7$. Variabel minat pasar dipresentasikan dengan fungsi keanggotaan bahu dan segitiga. Hasil pengolahan himpunan dengan program Matlab dapat terlihat seperti pada gambar di bawah ini.

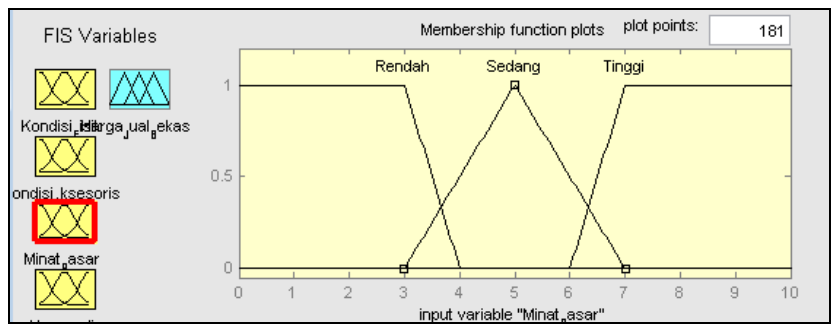

Gambar 3. Grafik Variabel Kondisi Minat Pasar

Dan persamaannya.

$\mu \operatorname{Rendah}[\mathrm{x}] \quad=\left\{\begin{array}{l}1 \\ (4-\mathrm{x}) /(4-3) \\ 0\end{array}\right.$

$$
\begin{aligned}
& ; 0 \leq x \leq 3 \\
& ; 3 \leq x \leq 4 \\
& ; \quad x \geq 4 \\
& ; 3 \leq x \leq 4 \\
& ; 4 \leq x \leq 7 \\
& ; x \leq 3 \text { atau } x \geq 7 \\
& \quad x \leq 6 \\
& ; 6 \leq x \leq 7 \\
& ; 7 \leq x \leq 10
\end{aligned}
$$

d) Variabel Harga Beli

Variabel Harga Beli didasarkan pada harga beli yang ada dipasaran saat ini. Range dan domain dari variabel harga beli dapat terlihat pada tabel 4.

Tabel 4. Harga beli

\begin{tabular}{ccc}
\hline No & Himpunan & Domain \\
\hline 1 & Sangat Murah & $8.000 .000-15.000 .000$ \\
2 & Murah & $15.000 .000-24.000 .000$ \\
3 & Normal & $24.000 .000-41.000 .000$ \\
4 & Mahal & $41.000 .000-53.000 .000$ \\
5 & Sangat Mahal & $53.000 .000-75.000 .000$ \\
\hline
\end{tabular}

Diketahui range harga beli adalah dari 8.000.000 sampai dengan 75.000.000. Variabel ini terdiri dari himpunan Sangat Murah, Murah, Normal, Mahal, Sangat Mahal, sehingga didapatkan: 


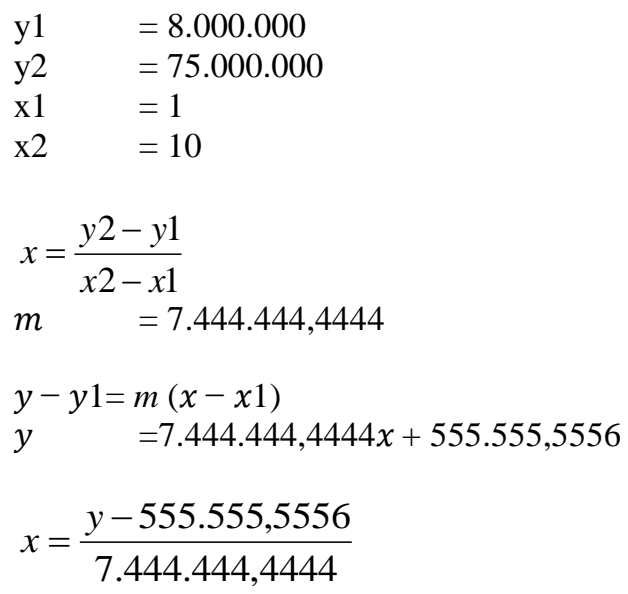

Tabel 5. Harga beli setelah dikonversi

\begin{tabular}{ccc}
\hline No & Himpunan & Domain \\
\hline 1 & Sangat Murah & $1-1,94$ \\
2 & Murah & $1,94-3,15$ \\
3 & Normal & $3,15-5,44$ \\
4 & Mahal & $5,44-7,045$ \\
5 & Sangat Mahal & $7,045-10$ \\
\hline
\end{tabular}

Variabel harga beli dibagi menjadi 5 himpunan fuzzy yaitu: Sangat Murah, Murah, Normal, Mahal, Sangat Mahal. Himpunan fuzzy Sangat Murah akan memiliki domain [1 - 1,94] dimana derajat keanggotaan Rendah tertinggi (=1) terletak pada angka 1,5. Himpunan fuzzy Murah memiliki domain $[1,94-3,15]$ dimana derajat keanggotaan Sedang tertinggi $(=1)$ terletak pada nilai 2,5. Himpunan fuzzy Normal akan memiliki domain [3,15 - 5,44] dimana derajat keanggotaan Tinggi tertinggi $(=1)$ terletak pada angka $\geq 4,5$. Himpunan fuzzy Mahal akan memiliki domain [5,44 - 7,045] dimana derajat keanggotaan Tinggi tertinggi $(=1)$ terletak pada angka $\geq 6,5$. Himpunan fuzzy Sangat Mahal akan memiliki domain [7,045 - 10] dimana derajat keanggotaan Tinggi tertinggi $(=1)$ terletak pada angka $\geq 8,5$. Hasil pengolahan himpunan dengan program Matlab dapat terlihat seperti pada gambar di bawah ini.

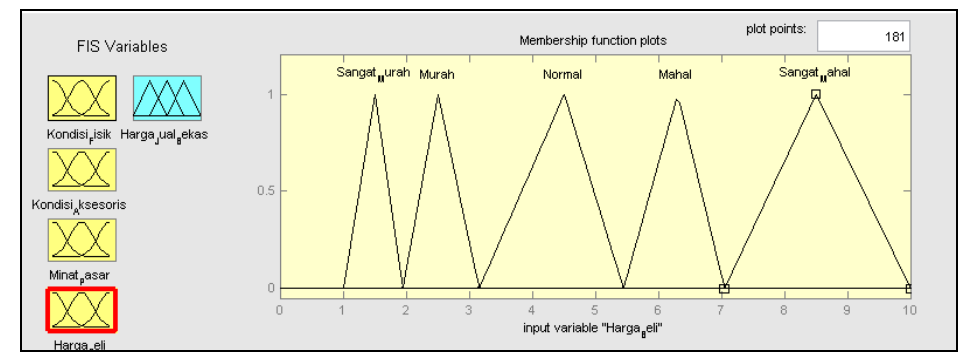

Gambar 4. Grafik Variabel Harga Beli

e) Variabel Harga Jual Bekas

Variabel harga jual bekas merupakan variabel output yang diharapkan dalam sistem ini. Harga jual bekas yang dihasilkan dari sistem ini diharapkan sesuai atau mendekati harga jual bekas yang ada dipasaran saat ini. Range dan domain dari variabel harga beli dapat terlihat pada tabel di bawah ini.

Tabel 6. Harga jual bekas

\begin{tabular}{ccc}
\hline No & Himpunan & Domain \\
\hline 1 & Sangat Rendah & $4.000 .000-11.000 .000$ \\
2 & Murah & $11.000 .000-19.000 .000$ \\
3 & Normal & $19.000 .000-35.000 .000$ \\
4 & Mahal & $35.000 .000-48.000 .000$ \\
5 & Sangat Mahal & $48.000 .000-70.000 .000$ \\
\hline
\end{tabular}

Diketahui range harga jual bekas adalah dari 4.000.000 sampai dengan 70.000.000. Variabel ini terdiri dari himpunan Sangat Rendah, Murah, Normal, Mahal, Sangat Mahal, sehingga didapatkan: 


$$
\begin{array}{ll}
\mathrm{y} 1 & =4.000 .000 \\
\mathrm{y} 2 & =70.000 .000 \\
\mathrm{x} 1 & =1 \\
\mathrm{x} 2 & =10 \\
x= & \frac{y 2-y 1}{x 2-x 1} \\
m \quad & =7.333 .333,3333 \\
y-y 1= & m(x-x 1) \\
y \quad=7.333 .333,3333 x-3.333 .333,3333 \\
x=\frac{y-3.333 .333,3333}{7.333 .333,3333}
\end{array}
$$

\begin{tabular}{|c|c|c|}
\hline No & Himpunan & Domain \\
\hline 1 & Sangat Rendah & $1-2$ \\
\hline 2 & Murah & $2-3,045$ \\
\hline 3 & Normal & $3,045-5,201$ \\
\hline 4 & Mahal & $5,201-7$ \\
\hline 5 & Sangat Mahal & $7-10$ \\
\hline
\end{tabular}

Tabel 7. Harga jual bekas setelah dikonversi

Variabel harga beli dibagi menjadi 5 himpunan fuzzy yaitu: Sangat Rendah, Murah, Normal, Mahal, Sangat Mahal. Himpunan fuzzy Sangat Rendah akan memiliki domain [1 - 2] dimana derajat keanggotaan Rendah tertinggi (=1) terletak pada angka 1,5. Himpunan fuzzy Murah memiliki domain [2 - 3,045] dimana derajat keanggotaan Sedang tertinggi $(=1)$ terletak pada nilai 2,5. Himpunan fuzzy Normal akan memiliki domain $[3,045-5,201]$ dimana derajat keanggotaan Tinggi tertinggi $(=1)$ terletak pada angka $\geq$ 4,5. Himpunan fuzzy Mahal akan memiliki domain [5,201 - 7] dimana derajat keanggotaan Tinggi tertinggi (=1) terletak pada angka $\geq 6,3$. Himpunan fuzzy Sangat Mahal akan memiliki domain [7 - 10] dimana derajat keanggotaan Tinggi tertinggi $(=1)$ terletak pada angka $\geq 8,5$. Hasil pengolahan himpunan dengan program Matlab dapat terlihat seperti pada gambar di bawah ini.

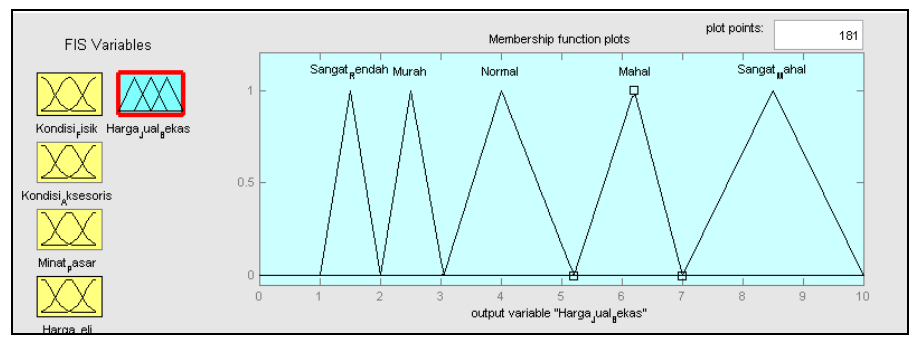

Gambar 5. Grafik Variabel Harga Jual Bekas

\subsubsection{Pembentukan Basis Pengetahuan Fuzzy}

Tahap berikutnya membentuk basis pengetahuan yang berisi aturan-aturan (rule) dalam bentuk $I F \ldots T H E N$ yang disesuaikan dengan penelitian yang telah dilakukan. Terdapat 13 aturan sebagai berikut:

[R1] IF KFisik is Bagus And KAksesoris is Baik And MinatPasar is Tinggi And HargaBeli is Sangat_Murah Then HargaJualBekas is Sangat_Rendah.

[R2] IF KFisik is Bagus And KAksesoris is Baik And MinatPasar is Tinggi And HargaBeli is Murah Then HargaJualBekas is Murah.

[R3] IF KFisik is Bagus And KAksesoris is Baik And MinatPasar is Tinggi And HargaBeli is Normal Then HargaJualBekas is Normal.

[R4] IF KFisik is Bagus And KAksesoris is Baik And MinatPasar is Tinggi And HargaBeli is Mahal Then HargaJualBekas is Mahal.

[R5] IF KFisik is Bagus And KAksesoris is Baik And MinatPasar is Tinggi And HargaBeli is Sangat_Mahal Then HargaJualBekas is Sangat_Mahal.

[R6] IF KFisik is Bagus And KAksesoris is Kurang And MinatPasar is Rendah And HargaBeli is Murah Then HargaJualBekas is Sangat_Rendah.

[R7] IF KFisik is Bagus And KAksesoris is Kurang And MinatPasar is Rendah And HargaBeli is Normal Then HargaJualBekas is Murah. 
[R8] IF KFisik is Bagus And KAksesoris is Kurang And MinatPasar is Rendah And HargaBeli is Mahal Then HargaJualBekas is Noramal.

[R9] IF KFisik is Bagus And KAksesoris is Kurang And MinatPasar is Rendah And HargaBeli is Sangat_Mahal Then HargaJualBekas is Mahal.

[R10] IF KFisik is Bagus And KAksesoris is Kurang And MinatPasar is Tinggi And HargaBeli is Murah Then HargaJualBekas is Sangat_Rendah.

[R11] IF KFisik is Bagus And KAksesoris is Kurang And MinatPasar is Tinggi And HargaBeli is Normal Then HargaJualBekas is Murah.

[R12] IF KFisik is Bagus And KAksesoris is Kurang And MinatPasar is Tinggi And HargaBeli is Mahal Then HargaJualBekas is Normal.

[R13] IF KFisik is Bagus And KAksesoris is Kurang And MinatPasar is Tinggi And HargaBeli is Sangat_Mahal Then HargaJualBekas is Mahal

\subsubsection{Aplikasi Fungsi Implikasi}

Fungsi ini digunakan untuk mendapatkan nilai $\alpha$-predikat hasil implikasi dengan cara memilih output himpunan fuzzy sesuai dengan derajat keanggotaan yang terkecil.

\subsubsection{Komposisi Antar - Rule}

Solusi himpunan fuzzy diperoleh dengan cara mengambil nilai maksimum aturan, kemudian menggunakannya untuk memodifikasi daerah fuzzy, dan mengaplikasikannya ke output dengan menggunakan operator OR (union).

\subsubsection{Defuzzyfikasi}

Input dari proses defuzzifikasi adalah suatu himpunan fuzzy yang diperoleh dari komposisi aturanaturan fuzzy, sedangkan output yang dihasilkan merupakan suatu bilangan pada domain himpunan fuzzy tersebut. Sehingga jika diberikan suatu himpunan fuzzy dalam range tertentu, maka harus diambil suatu nilai crsip tertentu sebagai output. Dan metode yang digunakan adalah metode centroid, dimana solusi crisp diperoleh dengan cara mengambil titik pusat $\left(Z^{*}\right)$ daerah fuzzy. Secara umum dirumuskan:

$Z^{*}=\frac{\int \mu(Z) Z d Z}{\int \mu(Z) d Z}$

Dari proses-proses fuzzyfikasi yang telah dilakukan diatas, maka akan didapatkan harga jual sepeda motor bekas.

\subsection{Implementasi Program}

Pengimplementasian program pada penelitian ini menggunakan bahasa pemrograman Matlab dalam menerapkan logika fuzzy infrence system Mamdani pada penentuan harga jual sepeda motor bekas. Berikut adalah hasil implementasi logika fuzzy infrence system Mamdani dalam penentuan harga jual sepeda motor bekas. Tahapan-tahapan yang perlu dilakukan diantaranya:

a. Pembentukan rule editor, yaitu tempat dimana rule-rule dikelola, baik itu untuk menambah, menghapus, dan juga mengubah rule. Pada rule editor lah rule dikelola agar nantinya sistem dapat menghasilkan output harga jual bekas sesuai dengan yang input yang dilakukan pada variabel-variabel input.

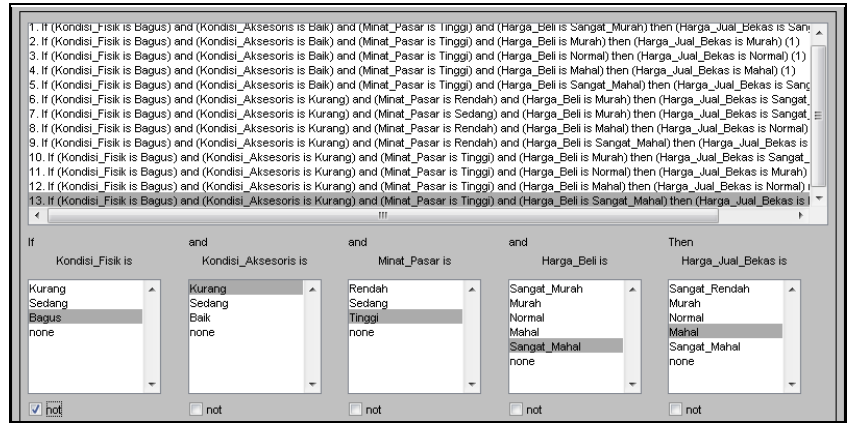

Gambar 7. Rule Editor 
b. Pembuatan prototyping yang merupakan bagian dari produk yang mengekspresikan logika maupun fisik antarmuka eksternal yang ditampilkan [5]. Tampilan graphic user interface yang merupakan tampilan hasil eksekusi program dan tempat memasukkan nilai pada tiap-tiap variabel input. Setelahnya dapat dilihat hasil atau output dari program tersebut. Tampilan program penentuan harga jual sepeda motor bekas dapat dilihat pada gambar di bawah ini.

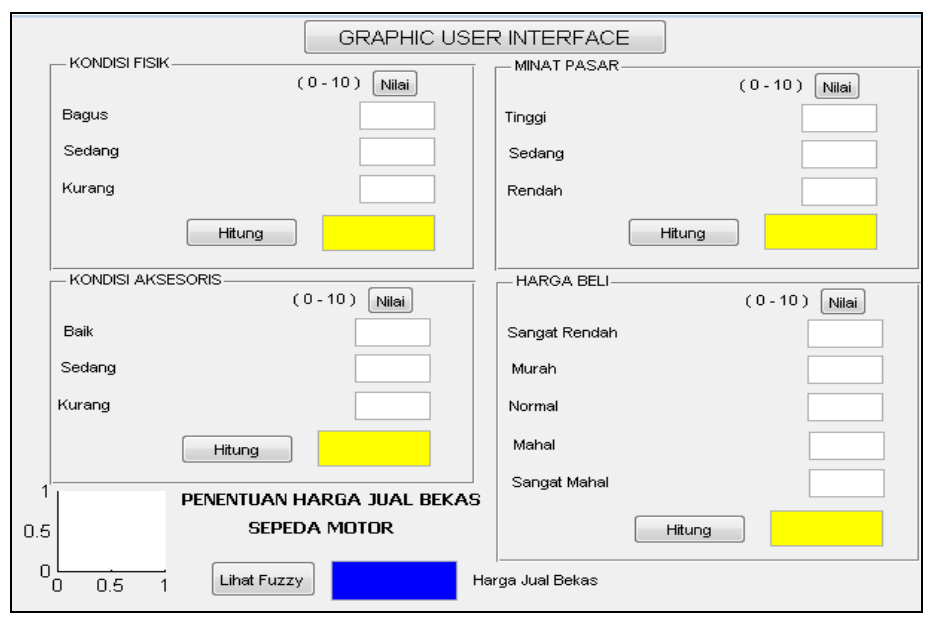

Gambar 6. Graphic User Interface

\section{KESIMPULAN}

Hasil dari penelitian ini dapat disimpulkan antara lain:

1) Penentuan harga jual sepeda motor bekas dapat menerapkan logika fuzzy infrence system Mamdani. Dengan ini dealer-dealer dapat menggunakan sistem ini untuk membantu menentukan harga jual sepeda motor bekas, dimana harga jual yang dihasilkan sudah sesuai dengan harga jual standart sepeda motor bekas di pasaran.

2) Penerapan logika fuzzy infrence system Mamdani untuk menentukan harga jual sepeda motor bekas ini dapat menggunakan Matlab R2009b dalam pemodelan sistemnya yang biasanya Matlab memang digunakan sebagai pendukung penelitian, sehingga bisa dikembangka dengan menggunakan alat bantu lain seperti Delphi, PHP, Visual Basic, Java dan lain sebagainya agar nantinya bisa didapatkan interface yang lebih interaktif bagi user dan dapat digunakan untuk halayak luas.

3) Penerapan logika fuzzy infrence system Mamdani disini hanya sebatas pada menentukan harga jual sepeda motor bekasnya saja, tidak sampai pada pengambilan keputusan apakah suatu dealer sepeda motor akan mengambil atau membeli sepeda motor bekas yang dijual ke dealer tersebut dengan mempertimbangkan kondisi-kondisi dari sepeda motor seperti kondisi fisik, aksesoris, minat pasar, harga beli baru dan juga stok barang dengan kesesuaian kebijakan dealer tersebut.

\section{DAFTAR PUSTAKA}

[1] Marimin, dan Nurul, (2010), Aplikasi Teknik Pengambilan Keputusan dalam Manajemen Rantai Pasok, IPB Press, Bogor.

[2] Efraim Turban, Jay E. Aronson, and Ting-Peng Liang. (2005). Decision Support System And Intelligent System-7th Ed. Pearson Education, New Jersey: Inc. Upper Saddle River.

[3] Kusumadewi, Sri, et al. (2006) Fuzzy Multi-Attribute Decision Making (Fuzzy MADM). Yogjakarta: Graha Ilmu.

[4] Eng, Agus Naba. (2009). Belajar Cepat Fuzzy Logic menggunakan Matlab. Yogyakarta: Andi Offset.

[5] Simarmata, Janner. (2010). Rekayasa Perangkat Lunak. Yogyakarta: Andi Offset. 